\title{
Toward a new normality in Via Paolo Sarpi (Milan, Italy)? Social behaviors and spatial transitions during and after the lockdown
}

\section{Mario Paris \& Fang Ying}

To cite this article: Mario Paris \& Fang Ying (2021) Toward a new normality in Via Paolo Sarpi (Milan, Italy)? Social behaviors and spatial transitions during and after the lockdown, Journal of Human Behavior in the Social Environment, 31:1-4, 305-324, DOI: 10.1080/10911359.2020.1823295

To link to this article: https://doi.org/10.1080/10911359.2020.1823295

Published online: 09 Apr 2021.

Submit your article to this journal $\square$

Q View related articles ๘

View Crossmark data $\asymp$ 


\title{
Toward a new normality in Via Paolo Sarpi (Milan, Italy)? Social behaviors and spatial transitions during and after the lockdown
}

\author{
Mario Paris $\mathbb{D D}^{\mathrm{a}}$ and Fang Ying ${ }^{\mathrm{b}}$

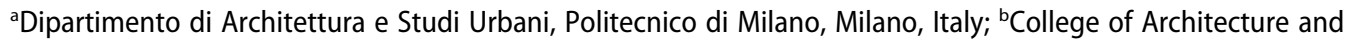 \\ Urban Planning, Tongji University, Shanghai, China
}

\begin{abstract}
During the COVID-19 crisis (February-September 2020), Lombardythe most populous region in Italy-suffered more than 101,705 contagions with more than 16,880 deaths. Such an amount of cases (38,9\% over the total Italian COVID-19 patients and $47,8 \%$ over Italian deaths) imposed a severe lockdown that affected ten million inhabitants in one of the larger urban regions of Europe that includes the cities of Milan, Bergamo, and Brescia. Social contact where forbidden, and civil rights and mobility dramatically reduced. Therefore, over two months, three urban values (the density, the proximity, and the continuous interaction) that shaped the European lifestyle in cities were considered dangerous. The urban space itself turned in a risky environment for its inhabitants. The disruptive result has been a general decline of urban public life, and this reduction has been evident in high streets and other public spaces. Hoping that the current situation will change rapidly, we recognize that we must adapt to a new normality, where public spaces and social encounters will still have a crucial role in cities. Regarding the rapid and profound transformation of social behaviors in Milan during the COVID-19 crisis, the research will be picking the focus on the street space as a suitable environment for converting more sociable anwctd healthy public spaces. Starting from the case of a multiethnic consolidated neighborhood in Milan (around Via Paolo Sarpi, a pedestrian-oriented street marked by the presence of the Chinese community), the proposed chapter explores how social behaviors and their spatial impacts changed-and adapted-during the lockdown. We will involve the analysis of the changes in the living practices of the street during the pandemic not only physically but also performed as booming social media connections. In the conclusions, we will point out how several reflections about the new normality that is rising out after this extra-ordinary situation at the local level, and how this original knowledge must support a new approach to the urban planning and territorial governance in the next years.
\end{abstract}

\section{KEYWORDS}

COVID-19; Milan; new normality; social behaviors; spatial transitions

\section{Introduction: Impact of COVID-19 in urban contexts and social behaviors in cities}

In a recent editorial, Batty (2020) compares the impact of the Coronavirus crisis in cities on a network affected by a dramatic shock. Usually, social and communication networks are

CONTACT Mario Paris mario.paris@polimi.it Dipartimento di Architettura e Studi Urbani, Politecnico di Milano DAStU, Via Bonardi, 9 - Edificio Nave, 20133 Milano, Italy 
composed of different clusters of nodes that reflect competitive human nature and their need to agglomerate. The flexibility of this pattern-based on the redundancy, the presence of weak and robust tiles, and the availability of alternatives-supports the lack of transmissions and the difficulties related to the reduction of social contacts. On the other hand, when the current structure is unable to sustain the continuity of the stream or the flow is interrupted by external agents-or self-containment policies, as in this case -, the whole network suffers a traumatic impact. This image is a powerful representation to figure out how COVID-19 affected the city as a socio-technical system (Hillier, 2012), where the spaces host relationships, interactions, and behaviors. This paper aims to understand how the imposed lockdown affected neighborhood as a discrete area with a living community inside. In parallel, we would focus on how its users/inhabitants responded to several restrictions that affected personal freedoms and rights, but also their living practices and "urban" interactions in public/shared spaces. During the crisis, the measures and activities undertaken to limit the adverse impact of the epidemic imposed a reflection about all those urban values and features (the density, the proximity, the free mobility, and the continuous exchange) that shaped the European lifestyle in cities. Journalists described the city as a locus of risk (Lai et al., 2020) due to the concentration and closeness of inhabitants. In parallel, a new sociality based on private spaces (as balconies or inner private courtyards) and social networks raised out. Therefore, not-face-to-face and digital interactions emerged, and the integration between consolidated and re-configurated urban behaviors needs to be overhauled. In fact, in the field of urban studies, several scholars (i.e., Connolly et al., 2020; Wolf, 2016) reflected on the role of urban patterns in the virus spreading and how urban design and density influenced the transmission chains of infectious diseases. Others focus on what public policies and spatial governance can learn from this forced experiment (Acuto, 2020). Previously, other studies demonstrated the role of social behaviors in the transmission of some typologies of virus (among others: Chretien et al., 2014; Kucharski et al., 2014). Simultaneously, we noticed a lack of contributions to the impacts of COVID-19 in the evolution of urban living practices and how these will evolve in the future. As recognized by Lak et al. (2020), the role of reduction of social interactions, face to face connections, and outdoor activities for declining the speed of virus spread is undeniable. The presence of health care facilities in compact urban areas, the flourishing of cooperative behaviors and solidarity within the local community, and the opportunities provided by the proximity where vital elements for the survival of a large part of the urban population during the lockdown. The disruptive, combinate result of this double trend has been a general decline of urban public life, and this reduction has been evident in high streets, and in all those public spaces that up to the pandemic supported the social encounter. Professor Batty (2020) argues that to understand what the "new normal" will look like, scholars need to consider the large number of networks that compose the contemporary city and work out how these will change as the pandemic is managed. In this paper, over the last months, we registered a complex set of reactions that produced different kinds of sociality, and we proposed several observations related to the ability of inhabitants to adapting or reconfiguring their behaviors. As planners and urban designers, these materials could be a factual basis to understand how the new normality will take place in our cities. Only understanding this reality, practitioners, policy-makers, and civil servants will support the evolution of social interactions in urban environments and produce more safe and healthier habitats for the future. 
After a brief introduction about the context of the research, ${ }^{1}$ we presented the results of a study developed in a consolidated neighborhood of the city of Milan over the last five months, through a qualitative and quantitative methodology, to observe the transformations of social interactions we detected during and after the lockdown (2.). In the following section (3.), we propose a set of suggestions taken out from this observation, and we discuss them in terms of spatial impacts and consequences on the social behaviors. Conclusions (4.) present our proposed integration in sociability taxonomy, able to comprehend interactions in digital and physical environments that marked the Coronavirus crisis. Besides, we pointed out how new behaviors and their spatial impacts (called "transitions") influenced the use of urban spaces and their future design. This process is crucial if we want to understand how cities and citizens respond to outbreaks of emerging infectious diseases and shape public actions able to produce long-term solutions. Just comprehending how people move, shop, interact, and socialize after Coivd-19, we can rethink current measures of spatial planning according to new societal challenges that we discover during the crisis.

\section{Materials and methods}

Usually, streets and public spaces in cities host all the urban populations and their social encounters. In these spaces-as recognized by Ghel (1987/2011, p. 14)_"People walk, sit, and talk. Functional, recreational, and social activities intertwine in all conceivable combinations". During the Coronavirus crisis, all the activities on the main street, including mobilizing, shopping, socializing, have been reduced or forbidden. The fragility of the system of relationships and interactions that we develop in urban spaces became evident, as well as the limits of the consolidated taxonomy for social behaviors, that does not consider new forms of interactions raised over the last months.

It is essential to examine the behavioral transformation during the different phases of the Coronavirus crisis to figure out what had happened about the sociability in urban spaces and what has been changing during the past months of global transmission. Therefore, the study discusses the street behavior studies developed by Mehta (2013), and it aims to propose an integrated taxonomy able to comprehend the phenomena that emerged during and after COVID-19. Vikas Mehta, as on of the first scholars who systematically classified street behaviors, created his classification applied to the sociology studies developed by Lofland (1998) and expanded the theory from Gehl (1987/2011), who built the famous taxonomy of outdoor activities. He identified three sociabilities of the street that he classified as "passive", "fleeting", and "enduring". Each classification depends on the intensity of contact conducted by different social relations visible on the street. Based on Mehta's taxonomy, we proposed the first model of stratified sociability to illustrate the internal social relationships, contact distances, frequently happening examples, and duration of social behaviors before COVID-19 (Figure 1).

The stratification indicates the proportion of social interaction on the street. The model conceptualizes an expansion of previous theories and is a comparative pattern for the exploration of changing behaviors during COVID-19 in the study. We had to focus on the neighborhood scale to appreciate these transformations, and we selected the area around Via Paolo Sarpi in Milan. Due to the restrictions during the lockdown and the absence of activities in the street, we decided to study behaviors integrating consolidated methods based on direct observation with an unconventional approach, proposing an 


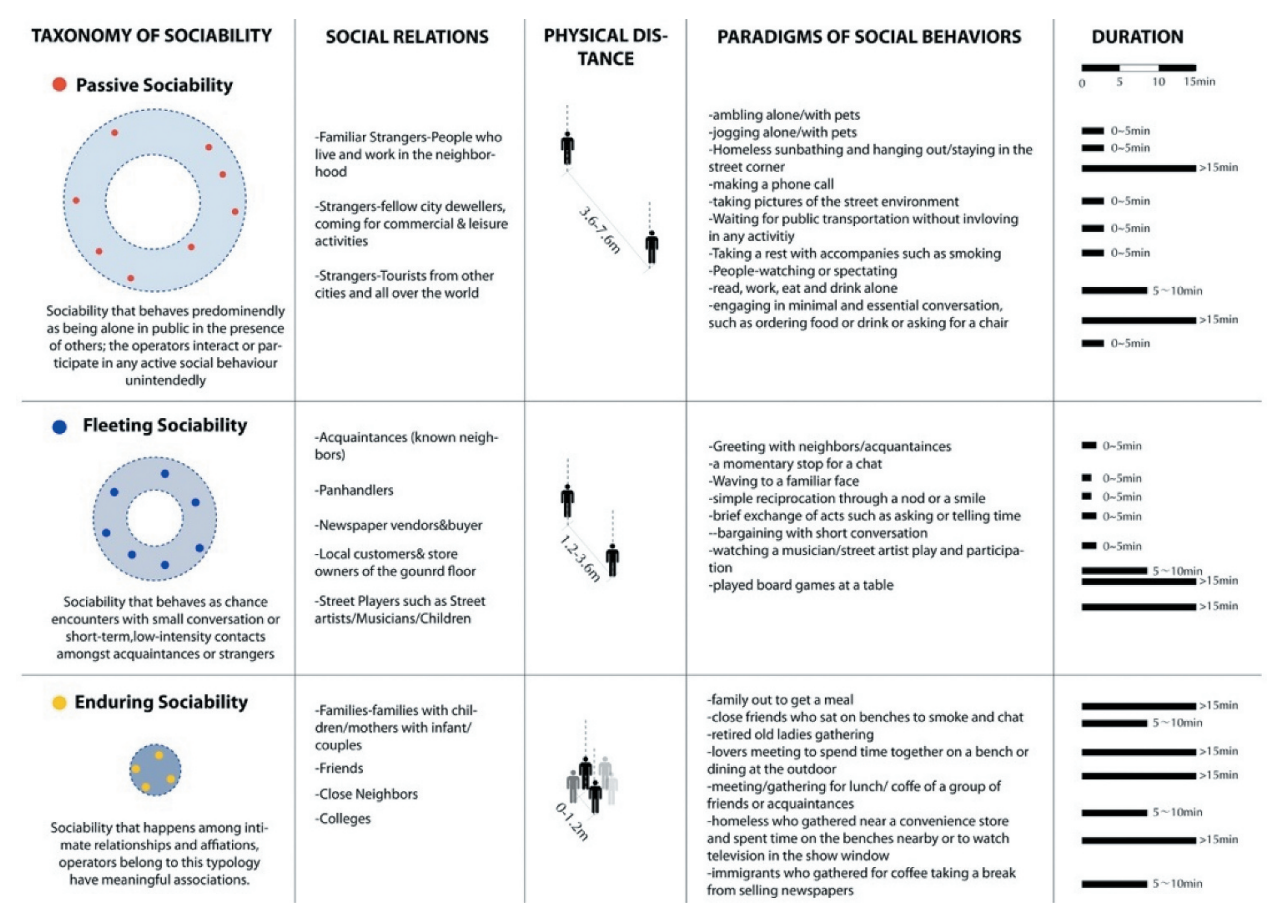

Figure 1. The stratified model of the taxonomy of sociability on the street based on Vikas Mehta's theory.

online survey and a semantic analysis of posts and status of neighbors in social media. Thanks to this material, we could test the effectiveness of the consolidated taxonomy, and we pointed out its limits to comprehend the evolution over the last months. To explore the new possibilities towards new normality, we integrate the existing taxonomy with specific categories that also involve the shift to social networks and digital interactions.

\section{Why Paolo Sarpi?}

During the COVID-19 crisis (February-September 2020), Lombardy-the most populous region in Italy-suffered more than 101,705 contagions with more than 16,880 deaths. Such an amount of cases (38,9\% over the total Italian COVID-19 patients and 47,8\% over Italian deaths) imposed a severe lockdown that affected ten million inhabitants (Istat, 2020) in one of the larger urban regions of Europe that includes the cities of Milan, Bergamo, and Brescia. Social contacts were forbidden, and civil rights and mobility dramatically reduced. Such an extra-ordinary approach imposes a radical transformation of the everyday life for the urban population and, therefore, we decided to study the impact of these measures on the local scale and on those consolidated neighborhoods that usually host vibrant urban life. Among several options, we selected Paolo Sarpi's district, located in the proximity of the historical core of Milan. The reasons for the selection of this specific case-study depend on three aspects.

On the one hand, it is a consolidated and multiethnic area, with a peculiar identity and a high quality in terms of urban landscape and fabric. Located between Piazza Gramsci and Piazzale Baiamonti, it's the main street that serves the Milanese Chinatown (Figure 2), full of independent Chinese shops and restaurants, and where inhabitants are Italians, but also 


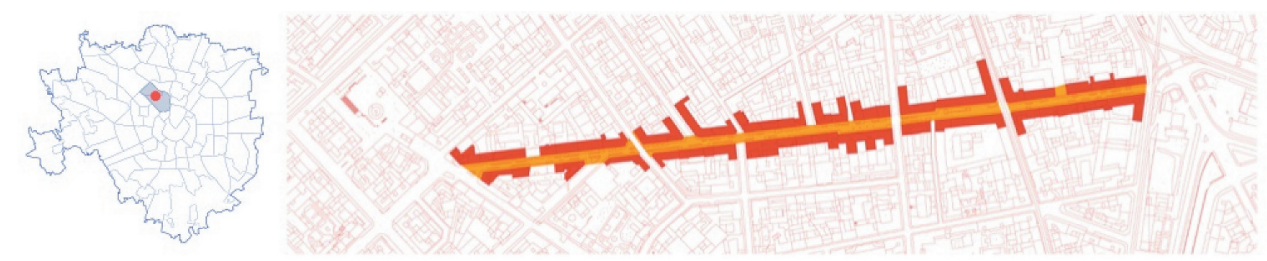

Figure 2. The location of Via Paolo Sarpi in Milan.

migrants of II or III generations. Therefore, the renovated public space, transformed in a pedestrian area in 2010-2011, supports the everyday life and social encounter of different cultures that share facilities and urban open spaces. The presence of Chinese entrepreneurs produces a dynamic local economy. Unlike other semi-central areas of Milan, this neighborhood is marked by a continuous and vibrant activity $24 / 7$, and these aspects together shaped over the years a definite identity, where the social behaviors are a vital element, and it became a paradigm of public and social space in Milan that supports young Milanese hanging out and gathering.

On the other hand, among the similar neighborhoods in Milan, we selected Paolo Sarpi because since 2010 is active on Facebook, the bottom-up group "Paolo Sarpi Social Street" (or PSSS, hereafter). ${ }^{2}$ This group gathered more than 14.000 neighbors who want to recreate social ties and use this tool to spread information and announcements about their district. This group is one of the most known and recognized in Milan. Over the last ten years and during the Coronavirus crisis, inhabitants of Paolo Sarpi have never stopped its pace of keeping internal social interaction. Therefore, during the lockdown of COVID-19, 'Paolo Sarpi Social Street' not only maintained the sense of neighbors' attachment but, more importantly, has probably influenced the sociability of the neighborhood profoundly. It has been a powerful platform for neighbors and strangers to fight isolation and loneliness by interacting online in a difficult time, and we had the opportunity to study the interactions through this platform. Besides, we selected this area to take advantage of our different cultures and language skills, to be able to interact with the two main cultural groups located in the area.

\section{Methodology and approach}

In his studies, Vikas Mehta used walk-by observations to analyze the pattern of sociability on the streets. In the past urban studies, this methodology was the most widely used as a fundamental tool (Bechtel et al., 1987). It's an efficient way to collect behavioral characteristics on social interaction that is visible in the physical environment (Francis, 1984; Marcus \& Francis, 1997; Whyte, 1980). Thanks to this technique, Mehta structured direct observations to record the details of all types of social behaviors (Mehta, 2007, 2014; V. Mehta \& Bosson, 2010). Through direct observation, we recorded the intensity and the contents of new-born social behaviors in Paolo Sarpi during COVID-19. It lasts from January 15th to June 15th in 2020. The data were collected comparatively from the period before COVID-19 (January 15th -March 10th) to the quarantine during COVID-19 (March 10th-June 15th).

As we explained in the previous section, over the last months, this option was ineffective to register other kinds of interactions, and we had to introduce two alternative methodologies to evaluate the social behaviors over these months: 


\section{The online survey}

We designed the interview questions to capture the changes people think about their social life. The data were collected from May 10th to June 15th, after the first month of lockdown. We asked people to consider what they valued on the street, with whom they would love to keep social interaction, their rapid responses since the lockdown, and their future expectations for Paolo Sarpi and the built environment. The survey included 65 respondents. $86.6 \%$ are the local dwellers, $12.3 \%$ who don't live in the neighborhood but have been interested in Paolo Sarpi. Nearly half of the respondents are from the age of $37-55(47.7 \%), 27.7 \%$ are young people from the age of $25-36$, and $18.5 \%$ are old and retired people over 56 years old. The result was a behavioral map to explore the relationship between behaviors and environmental characteristics (Ittelson, 1970). For testing their social relationships, the investigation examines if and how they change their relations regarding passive, fleeting, and enduring sociability. We asked about their feelings of social life before and during the lockdown, and about their concerns with family members or people with whom they share spaces. Besides, the survey keeps questioning if they were feeling closer to their neighbors and if they knew more people during a lockdown or not. We asked if they enlarged their social circle beyond the neighborhood with the platform of social media. The result of the survey indicates that behaviors fastly changed to survive and maintain the social interaction in the emergency of crisis, which is natural humanity, unforeseen by urban planners (Masten \& Motti-Stefanidi, 2020; Nitschke et al., 2020). As illustrated in Paolo Sarpi, human resilience represents the human spirit in times of struggle or catastrophe (Peters, 2020).

\section{The semantic analysis of online interactions in the "Paolo Sarpi Social Street" Facebook group}

The direct observation of virtual interactions recorded a sample of 3,534 events of sociability from January $15^{\text {th }}$ to June $15^{\text {th }}$ on the PSSS group, posted by neighbors, local companies, shop tenants, and local associations. We focused on several keywords that show the attitude and the aims of each event and/or interaction to define the quality of the exchanges raised through this media. Through the virtual observation of the activities of neighbors on Facebook, we could track the ongoing social behaviors and remedy the limitation of conventional physical observation. "Paolo Sarpi Social Street" established a robust digital infrastructure and has been more activated than ever. The online platform provides new opportunities for sociability and, to some extent, replaced the suspended social activities that happened physically. Residents and neighbors have been keeping their daily connection and cooperation in the neighborhood.

\section{Results: What happened in Paolo Sarpi?}

\section{Variations in consolidate sociability in the physical environment}

Answers of users of PSSS give a fast and general impression on the rapid responses from people since the lockdown, and we ask them to write if and how they have participated in any mutual assistance or solidarity group actions aimed at helping others since the lockdown (Figure 3); 93.8\% of people among respondents have had engaged in assisting 


\section{$24.1 \%$}

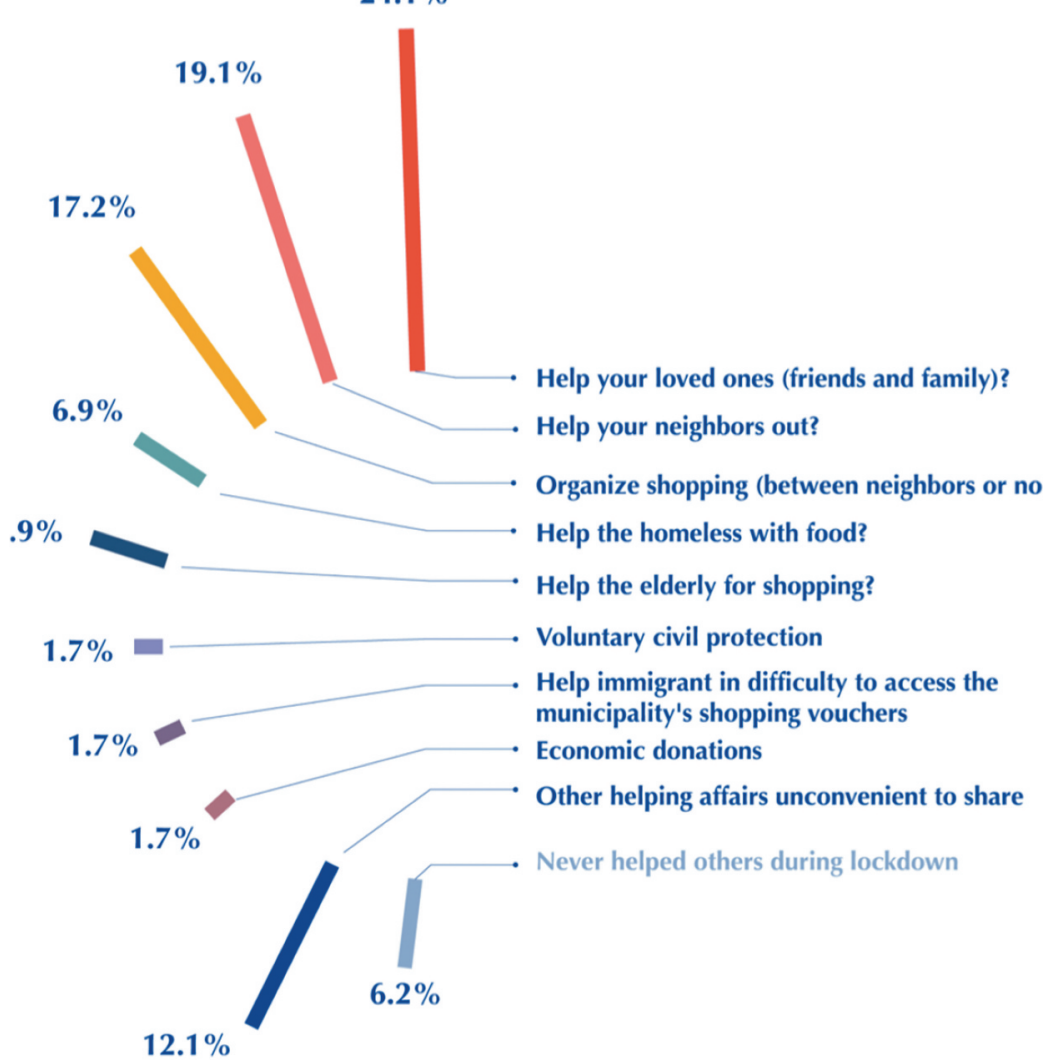

Figure 3. Participation in mutual assistance or solidarity group actions in Paolo Sarpi (During COVID-19).

behaviors as "helping out friends, families, and neighbors". Many interesting performances were described, such as "organizing shopping-together between neighbors, voluntary food delivery for the elderly and the disabled, helping migrants to access the municipality's shopping vouchers in the emergency ....". Therefore, there is a sense of polarization of social life before and during COVID-19 (Figure 4).
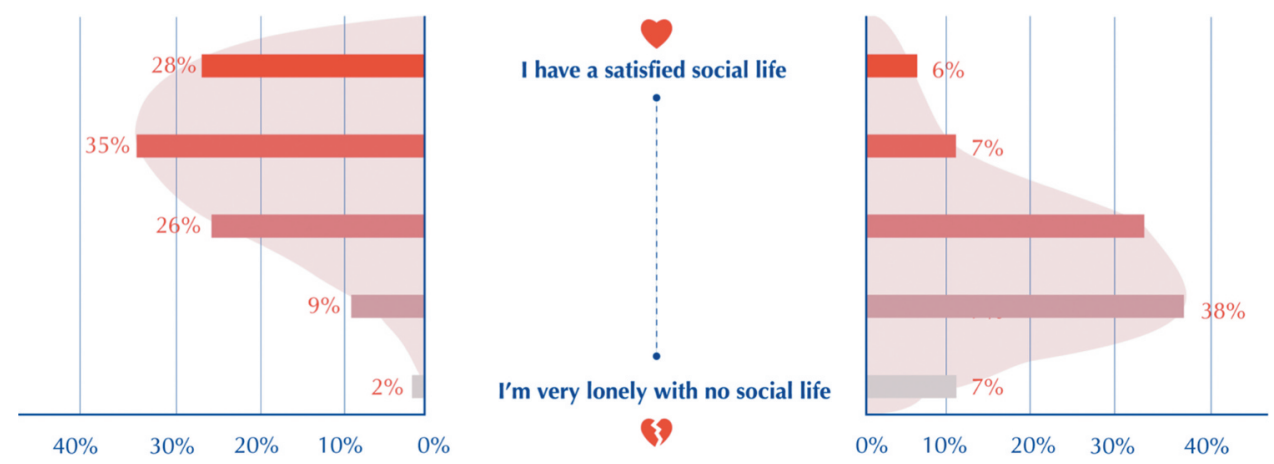

Figure 4. Degree of satisfaction on social life in Paolo Sarpi: Before and during COVID-19. 
Respondents are satisfied with their social life by giving scores of 4 or 5 among $63 \%$ of them. While in the quarantine, only $6 \%$ of respondents are completely satisfied with their social life, while over $45 \%$ of them show passivism. "I live alone in my apartment. There's no social life at all", said one interviewed from the age of 19-24. No matter how social life is transforming in a hidden new way by the pandemic, the self-evaluation of social life by the residents is decreasing. Most people sensed a decrease in their everyday life, especially at the beginning of the lockdown. Secondly, the enduring sociability of the neighborhood is getting stronger during the lockdown. More people are living in a closer relationship with their family members during the lockdown. COVID-19 amplified the sense of " home" (Fuchs, 2020). 31.3\% of respondents assess themselves as much more closely with families and roommates, concerning the lockdown provided new opportunities to be with them in a shrinking social space: home. Thirdly, fleeting sociability increased. $49.9 \%$ of people think they are living in a closer relationship with their neighbors and acquaintances. $35 \%$ of people think their social relations with neighbors were not negatively affected due to COVID-19. One of the interviewed said: "During the lockdown, I ordered food and consumed in the restaurant where I used to eat because I want to help out the store owners because I don't want to see them break down. I'll personally order more than before and advertise for them as well on Facebook for letting more people know them". Moreover, many people are enlarging their social circle inside the neighborhood during the lockdown. $38.5 \%$ of the respondents were getting in touch with more neighbors that they did not know before the pandemic. The contact, such as balcony concert or other online cooperative activities, provided unexpected opportunities for new connections and new relationships. Finally, the answers about passive sociability are more contradictory. The passive sociality refers to encounters among strangers in the physical environment, and this is an option radically reduced during the lockdown. However, social media couldn't equally replace the interactions that spontaneously flourish in open spaces. There are $67.7 \%$ of respondents who think that social media have nothing to help them with gaining some new relationship among strangers: "It's impossible that social media sufficiently compensate for the big void raised by the lockdown. I would more like to make friends with the one I could meet in the future, the one in Paolo Sarpi like me", answered by a respondent.

\section{Raising of new forms of sociability in the digital environment during COVID-19 lockdown}

We compared and analyzed these data dividing them into four phases (Figure 5). The first phase started before the pandemic, from January 15th to March 3rd, recorded 863 events,
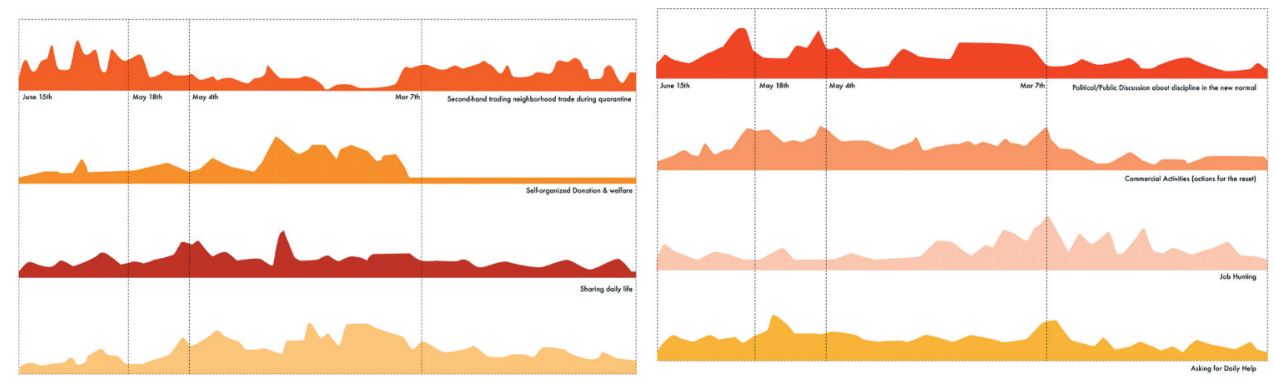

Figure 5. Variations of behaviors in different phases. 
17.9 per day on average. The engagement on Facebook manifests stable activities such as public discussion about hot-topics and the neighborhood, or regular secondhand trade. The second phase started from March 7th to May 4th. This period was the most challenging time, when people suffered in the fear and recession of lockdown. National and regional authorities defined restrictive measures that suspended most of the physical leisure, public, social activities. During this time, the intensity of activities on Facebook displays a sharp increase in all of the sociabilities: 1,786 events of activities, 29.8 per day on average, exhibiting as booming commercial activities for advertising (24.8\%), inquiry, and answers for the uncertainty (15.7\%), job hunting for a temporary living $(7.3 \%)$, public discussion on Facebook expressing individual opinions (28.9\%), etc. Numerous users are expressing their optimism by sharing the beauty of daily life and encouraging the public (35.8\%). The third phase, from May 4th to May 18th, embraced the first reset of the city with partly reopening of restaurants, essential street business, needed community services such as electronic repair store, bicycle shops, printing stores, and so on. The data show a slight decrease in the intensity of activities, 385 events, and 27.5 per day on average. During this phase, people started to step out of rooms and go back to their cherished outdoor spaces. People were attempting new ways of social engagement towards the new normality and still mainly relied on social media. Although there's a tendency indicating that social behaviors are gradually turning from public anxiety to public appealing, from discussions with the topic of public health and virus to the possibilities of new outdoor activities. The fourth phase, from May 18th to June 15th, faced a gradual reopening of the most street business.

After this moment, the intensity on Facebook reached a stable point, recording 500 events, 20 per day on average, even though there are still many small businesses that couldn't reopen due to different reasons. The last phase of observation shows a trend of the virtual interaction while at the same time, indicates that the public became more rational and confident to prepare for a post-pandemic phase.

Every new entry that people posted kept on Facebook and contain information indicates a new pattern of behaviors. It helps us to analyze how people engaged with the characteristics of the street and digital environment. We classified the new-born behaviors into eight main types:

- Online inquiry \& answers;

- Job hunting \& employing;

- Self-organized donation \& welfare;

- secondhand trading neighborhood trade during quarantine;

- Commercial activities;

- Political/public discussion about governance in the new normal;

- Sharing everyday life;

- Social activities/street events/amusement.

The record follows the classification (Figure 6). The blogs with no comments and nonsocialrelated were filtered and not counted in the observations.

\section{Discussion and conclusions}

Observations and online surveys provided a snapshot of the changing patterns of activities and behaviors in Paolo Sarpi during and after the Coronavirus crisis. They 


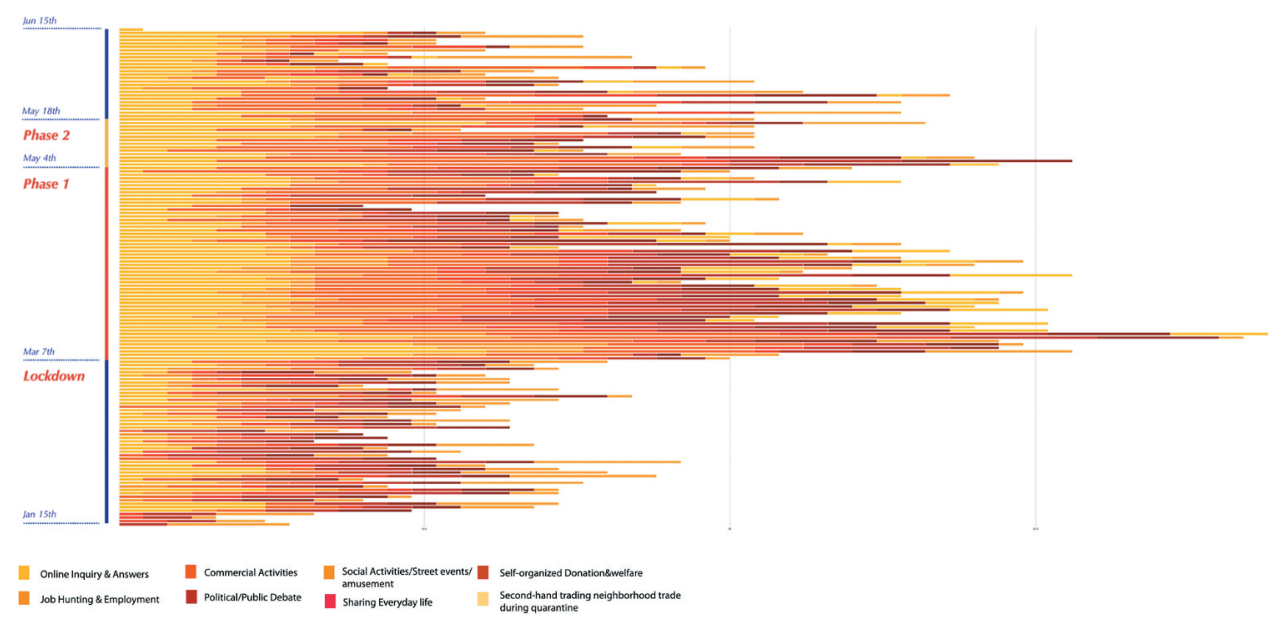

Figure 6. Record of everyday virtual observation on "social street" motion frequency of social activities during COVID-19 on Facebook.

show how a set of new interactions that raised and, in parallel, how the consolidated taxonomy of sociability was unable to comprehend those new forms of interaction. We are conscious of the limits connected to a study based on short-term observations and a limited amount of answers to the online survey. Still, we think that these could be an interesting platform to figure out some insights that further studies and reflections will deepen in the future. In our opinion, it is a research that tries to point out several ideas as a base for the public action, and the governance will be useful in this phase of reaction to the COVID-19 crisis. The new physical and digital behaviors manifest more complex characteristics, and we needed a new taxonomy to classify them, using different categories form the Mehta's one, that is still useful working only with actions developed in physical environments. The proposed is the first attempt that we will refine in the future but, at the same time, is an original perspective on the emergent challenges for public and private actors in cities and urban environments.

\section{A proposal for an integrated taxonomy for sociability}

The overlapping between virtual and physical interactions indicates the diversification of social contact happening in the virtual world and, thus, the complexity of each category. When a specific behavior occurs during the lockdown, it appears in parallel on social media and be operated in the real world (such as mask distribution and scheduled concert). It is hard to tell precisely with whom, where, and how long it usually lasts, because the possibility for all the dimensions of sociability is diversified and, sometimes, contradictory. As a result, we propose a new stratified taxonomy as an expansion of the former one. We re-defined the Mehta's categories (Passive, fleeting, and enduring sociability), and we integrated them with the other three (Needed, positive, and unpredictable sociability). 


\section{Consolidated categories (Passive, fleeting, and enduring sociability)}

During COVID-19, the featured behavior of Passive sociability, the identification of encounters among strangers is widening. 'Being alone' in public in the presence of others is expanded in multiple ways in the virtual world. The physical environment has no longer behave as a limitation and pure contain passive sociability. Strangers are engaging in social interaction with more choices: no matter from people sharing daily life, greeting, and encouraging with each other, browse political events and discussions in the virtual world, or engaging in balcony concert, or strolling with a pet on the empty street in the physical world.

The occasional encounters between neighbors, acquaintances who would start small chitchat and conversation also present various ways virtually and physically still represent the fleeting sociability. The short-term low-intensity contacts happen in bottom-up donation, balcony concert, urgent trade for daily supplies, and 'playful' amusement, such as open-air pilates in the park. The fleeting sociability also increased its complexity due to the booming behaviors between neighbors that improved their cooperative interactions (supporting each other, donating, sharing goods and time, etc.).

The enduring sociability, which previously conducted by intimate relationships and affiliations, is hard to track because the places for supporting these activities of meeting, gathering between families and friends now became the 'home' as a private space. However, 'meaningful associations' have different presentations: Donation activities, mask distribution, conversation in police patrol, etc. Enduring sociability, in this case, seems to become shrinkage in contrast to the formers. But we should take into account that the intimate groups, limited in condensed social space, home, were getting closer with their family members physically and participated in longer communicating, eating, and enjoying the street as usual before the lockdown.

Together with these consolidate categories, we enlarge the pattern adding other three:

\section{Needed sociability}

We defined the "Needed sociality" (Figure 7) as the interactions that happen for essential basics. People respond to survival and how people fight for their health and fundamental living condition. Needed sociality aims at an exchange for problem-solving, from which residents usually have a clear and significant goal. Online inquiry and answers are one of the most common needed behaviors in Paolo Sarpi during COVID-19. The overnight lockdown raised a lot of uncertainty, especially the inaccessibility of important information. Lack of crucial data and awareness of essential services such as printing store, sewer, laundry, electronic equipment repair, plumber, pushed people to ask their neighbors for help on Facebook. Such social interaction is rapidly being established. The inquiry for urgent and daily services frequently showed in the virtual observation, such as: "I have to furnish the house, and I need everything (pots, plates, glasses, etc.). Apart from Ikea, are there any shops that sell housewares with a good quality/price ratio? ". Job Hunting and Employment is another paradigmatic needed behavior.

Through the lockdown, many individuals have lost their previous jobs, or they were forced out of work for months. The recession made these people hard to have a source of income to sustain our lives. Therefore, many people started to use the online platform to a job temporarily to fund a life. Such people described their sociability as a way to engage in compelled behaviors. A mother wrote: "My daughter Agata is 16 years old (she attended 


\begin{tabular}{|c|c|c|}
\hline $\begin{array}{l}\text { Types of behaviors in virtual } \\
\text { observation }\end{array}$ & Online Inquiry \& Answers & Job Hunting \& Employment \\
\hline $\begin{array}{l}\text { Frequent Social activities in } \\
\text { virtual observation }\end{array}$ & $\begin{array}{l}\text { - Inquiry for medical help\& essential facilites (emer- } \\
\text { gency treatment, access medical and sanitary such as } \\
\text { masks) } \\
\text {-Seeking information of daily services that's missing } \\
\text { due to lockdown of daily services such as repairment } \\
\text { of electronic equipment, bank, printing, laundry ser- } \\
\text { vice, etc. } \\
\text {-Inquiry for accessing slow mobility(bicycle) that's } \\
\text { booming with the reopen } \\
\text {-Inquiry for accessing new-born virual tools/online } \\
\text { platform such as app esselunga } \\
\text {-Lost\&Found } \\
\text {-Seeking recommendation for hairdresser/local taste\& } \\
\text { personal care institution } \\
\text {-Inquiry for accessing Plants/upholsterer }\end{array}$ & $\begin{array}{l}\text {-Seeking oppurtunity for slow-skilled job such as } \\
\text { home decoration, baby-sitting, nursery } \\
\text { - Seeking oppurtunity for professional job such as } \\
\text { home tutor,family psychologist } \\
\text { - Employing short-term labor such as dishwashing } \\
\text { technician, plumber or handyman to fix the ignition } \\
\text { lock. }\end{array}$ \\
\hline
\end{tabular}

Figure 7. Needed sociability in Paolo Sarpi.

the second year of classical high school) offers for help elementary and middle school tasks for children in June. Or simply for $2 / 3$ hours babysitting daily morning or afternoon. Please write or contact me with any information. Thank you!"

\section{Positive sociability}

We describe the social behaviors that aim to improve the quality of life and recall the social connection for well-being and comfort psychologically as "Positive sociability"(Figure 8). The commercial-related exchanges among store owners and residents are one of the most frequent behaviors during the observation. The lockdown raised a sharp increase in online service for independent stores to survive. Restaurants, flower stores, mask makers, and handicraftsmen post their delivery information on Facebook. These brief advertising behaviors led to interactions among neighbors who want to support their cherished stores and maintain pleasure.

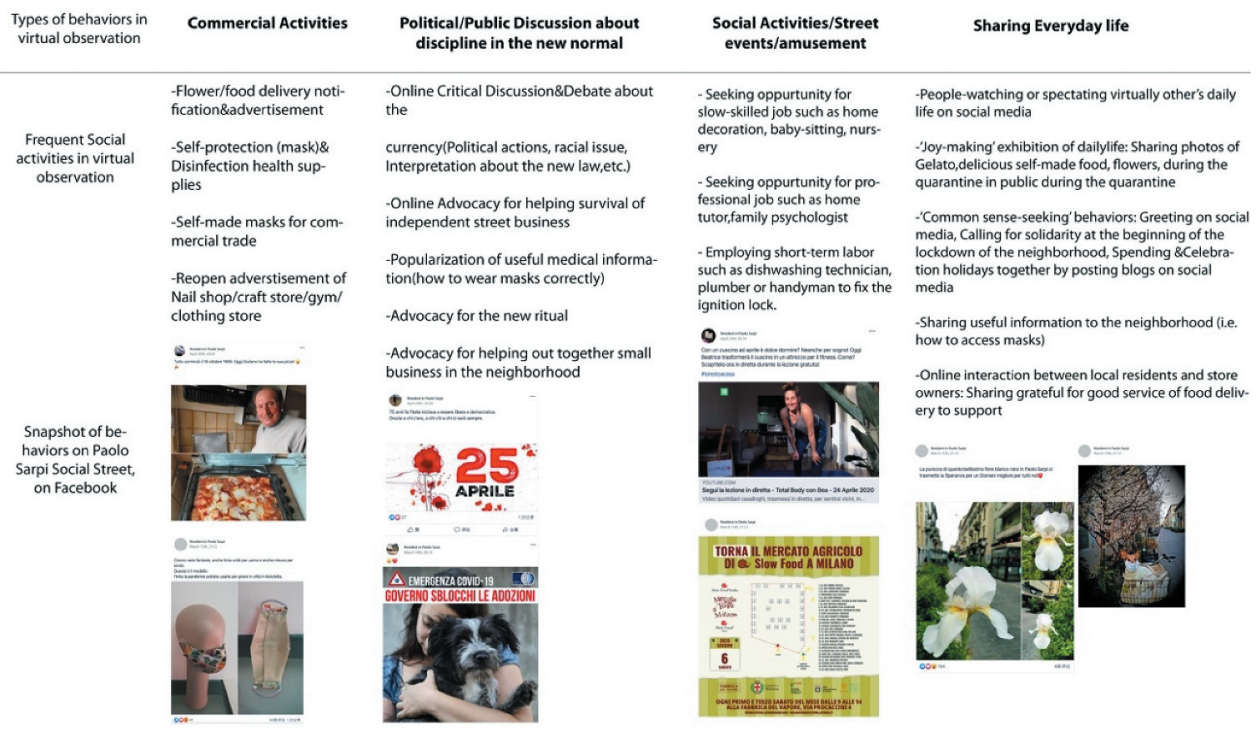

Figure 8. Positive sociability in Paolo Sarpi. 
As a fast-food maker wrote on March $15^{\text {th. }}$ "Good morning, everyone, and thank you for welcoming us to the group! Considering the situation, I take advantage of it to share it with you. We deliver rice, risotto, flour for polenta, and saffron throughout Milan! Please contact us!" Foremost, engagement in unconventional street events and amusement and sharing everyday life to the public on Facebook are prevalent during COVID-19. These behaviors with interactive participation among strangers or familiar neighbors provided much-needed relaxation and comfort during the pandemic panic. One of the users posted: "Here's what I would love to share with you guys. It was a really unexpected surprise in Paolo Sarpi last night. I went out after dinner for a walk and reached via Sarpi. I heard a piano playing close. I approached and escorted a motorcycle in front, and one behind, I see a young pianist on a small mobile platform pulled by a bike, a tandem with a single boy pedaling. He would stop for a while and then go on. Several people stopped and followed. People looked out onto balconies and windows. A nice moment. Then I learned that the pianist was Noemi Perrone and the initiative in the context of the Piano City Milano exhibition". His description recorded the unique sociability after a month of lockdown, which, more importantly, raised a lot of comments from other residents who like his sharing. Some bottom-up organization has been seeking ways for social interaction towards the new normality. For instance, some of them tried to restart new open-air activities in public space: “Tomorrow welcome to our Pilates at park Sempione, let's embrace the new ways of being together in green space!" Often these activities also share information about social distancing and security measures: "Our outdoor workshops! Guess what we have? Music! Dance! Creative workshops and theater games! More than you can think about! We will obey the hygiene condition and social distancing for everyone, come and join us!"

\section{Unpredictable sociability}

We called "Unpredictable sociability" (Figure 9) the interaction that residents created in Paolo Sarpi as a resistance to the emergency of crisis. These interactions presented a great power that is far more than urban planners could anticipate. The unpredictable sociability may develop from needed or positive sociability. It means more than the individual

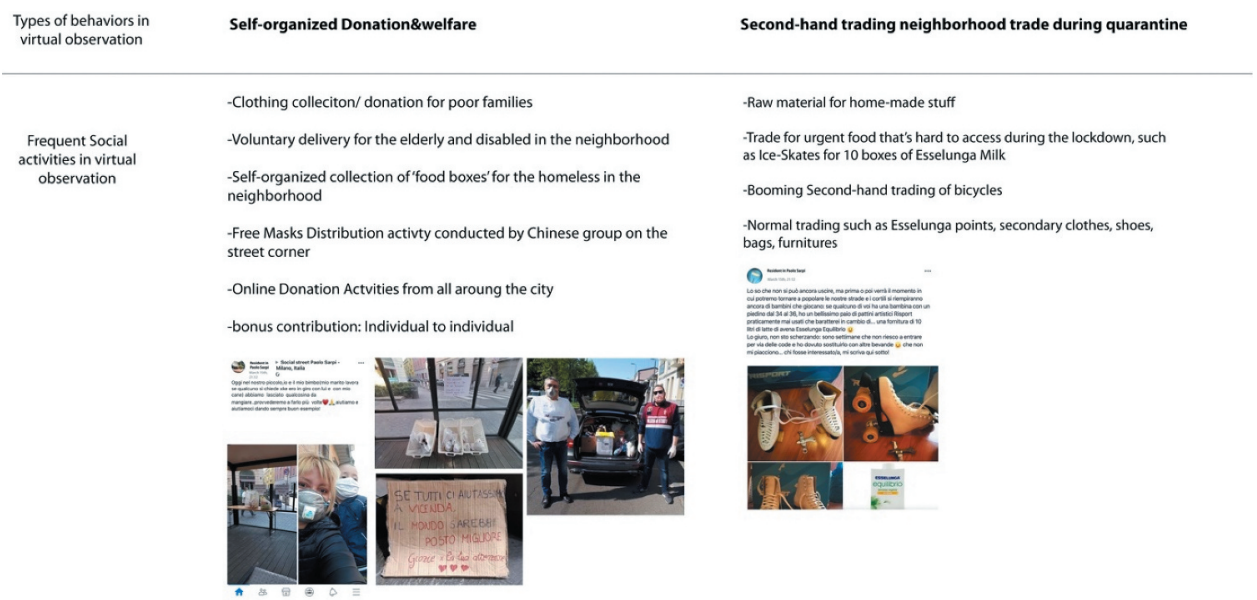

Figure 9. Unpredictable sociability in Paolo Sarpi. 
demands for essentiality or pleasant: it represents the power of solidarity and cooperation as a neighborhood.

Self-organized donation is the most prominent behavior in this classification. The youth started voluntary delivery for the elderly and disabled in the neighborhood: "Hello everyone, Maybe we're not the first (and we definitely won't be the last!), but we offer two pairs of toned arms for shopping or some commission (pharmacy, postal, tobacco, etc.) for those who can't or don't feel like doing it. We are willing to help anyone in the area. If you need anything, write in private, and we'll agree. Come on, everyone!-Laura and Lorenzo", said a couple living in Via Sarpi. Another volunteer post: "For elderly or disabled people in the area, my husband and I are available to bring groceries or medicine home. Thanks!" Some bottom-up campaigns quickly formed in a short time to deal with the crisis and appealed donations: "With some friends, we're distributing food and clothing to people with no fixed residence. Of course, we're impossible now, but as soon as we can get out again, they will need it. Since we're at home, why not tidy up the cabinets to pass the time? If you have things you don't use anymore, they will be very welcome. Thank you, I know you'll be great as always!" Numerous people commented and interacted, and more similar donations were motivated to start-up to help others.

\section{Towards new normality? Behavioral transformations and four emerging transitions}

The analysis of digital environments makes a difference in the previous social habit and raised interventions to form a new pattern of social behaviors. During COVID-19, measures blocked the majority of physical interaction, except the ones related to essential demands. The booming of the Facebook group for Paolo Sarpi, which provides a virtual room for maintaining necessary and additional social connections, plays a significant role in regenerating the relationship between people and space. The interaction between people on social media became indirect, with the virtual platform, and results in a further negotiation and plan of how people would use the space with different needs and special activities under lockdown.

With an overview of the hypothesis of the study and the update of the new taxonomy for Paolo Sarpi, we defined three lessons learned of the changing behavioral pattern:

- The emerged social behaviors indicate that previous boundaries between three categories are becoming blurring. There is some overlapping between passive, fleeting, and enduring sociability. The classification of these activities is not precise, and every single action could expand to the other groups of activities. For instance, a dweller could spectate the balcony concert of his neighbors, as a simple observer (Passive sociability). Suddenly, he can play his instrument, or he starts singing. Therefore he changes his role, assuming a more participative attitude in the show (Fleeting sociability).

- Social behaviors recorded and posted have a dual nature. Instead of what happened in physical space, posts on social media could be both short-term and long-term effects. On the one hand, the short-term means the conversation may be intensely happening as soon as it is posted (such as political and hot issue discussion, greeting to neighbors). On the other hand, interaction online is permanently preserved, and communication under blogs is continuous. Posts remain, and it's possible that one comment to the previous blog days or months ago raise another new discussion. The new sociabilities, in other words, can be continued, and street-life during COVID-19 is 'sticky' due to the existence of social media. 
- The sociability on the street is a spatial correlation. The online survey found that extensive interaction between global internet users beyond the neighborhood trends to be ineffective. The locals are more willing to relate to someone they can access. They try to be part of a comunità-spatially and physically linked-more than a pure community of interests. Unlike online communication, discussion, and offline accomplishment with neighbors, the browsing over the world is predominantly instant written in water, which doesn't help for the sociable pleasure for residents.

The rapidly transformed sociability in Paolo Sarpi indicates a changing pattern of the use of public/shared space and the living practices developed by its inhabitants. How people comprise social activities and their spatial occupancy (Goličnik \& Thompson, 2010) are reforming. Accordingly, the relationship between human behaviors and street environments changes. Streetlife, as argued in the proposed case-study, is being reshaped toward the new normality with the transformation of the internal relationship between the social behaviors and built environment. With the data collected on Facebook, we made a combined behavioral mapping (Figures 10-13) of the plan of the Via Paolo Sarpi, locating the activities that often happened during the observed period. The activities are classified and mapped following the new taxonomy described in the previous section. Throughout the comparative mapping before and during COVID-19, we can identify the hidden pattern that has been changing and reshaping. We distinguish four main changes that we called "transitions".

\section{Transition 1: Pattern of spatial occupation. From single to multiple}

The street artifacts are one of the most crucial human-scale characteristics for establishing sociable streets physically (Mehta, 2019). The "dinning booths" in Via Paolo Sarpi, for instance, were previously sociable places for people to operate enduring sociability, such as eating, drinking coffee with friends outside. During COVID-19, such street artifacts converted from
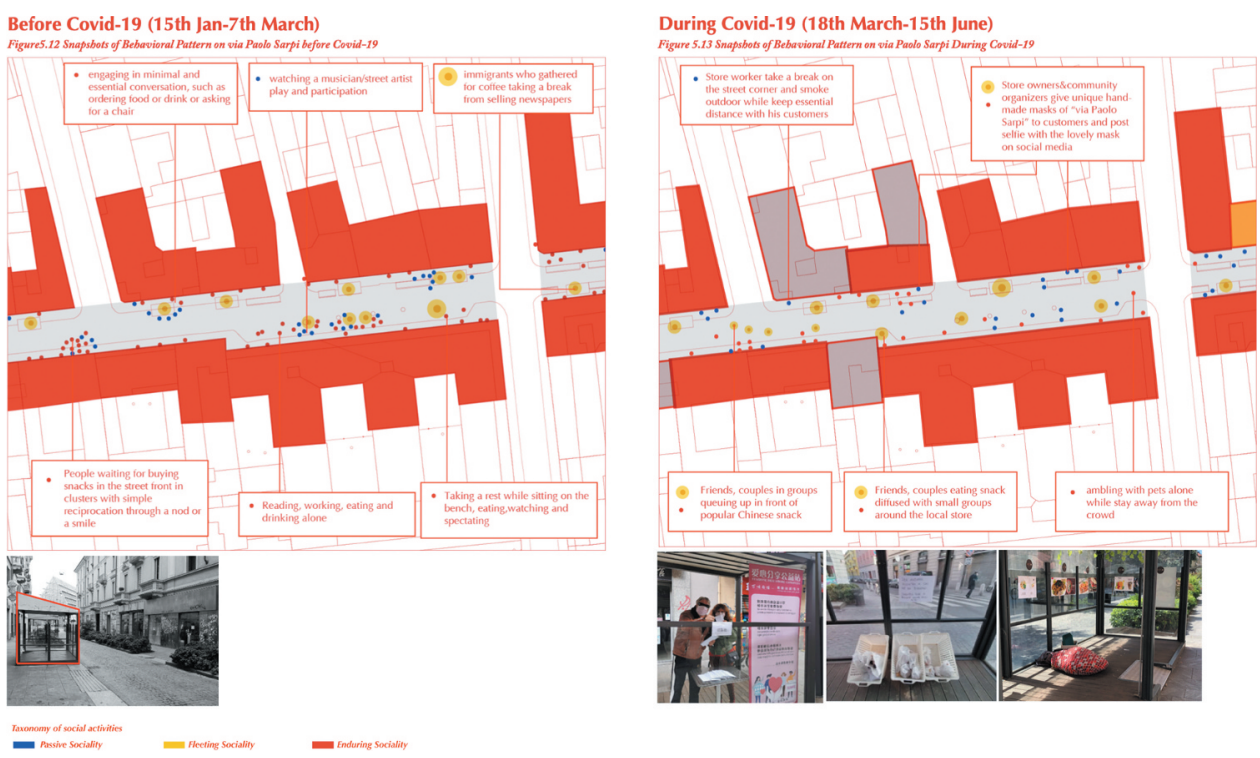

Figure 10. Snapshots of behavioral mapping on via Paolo Sarpi before and during COVID-19. 

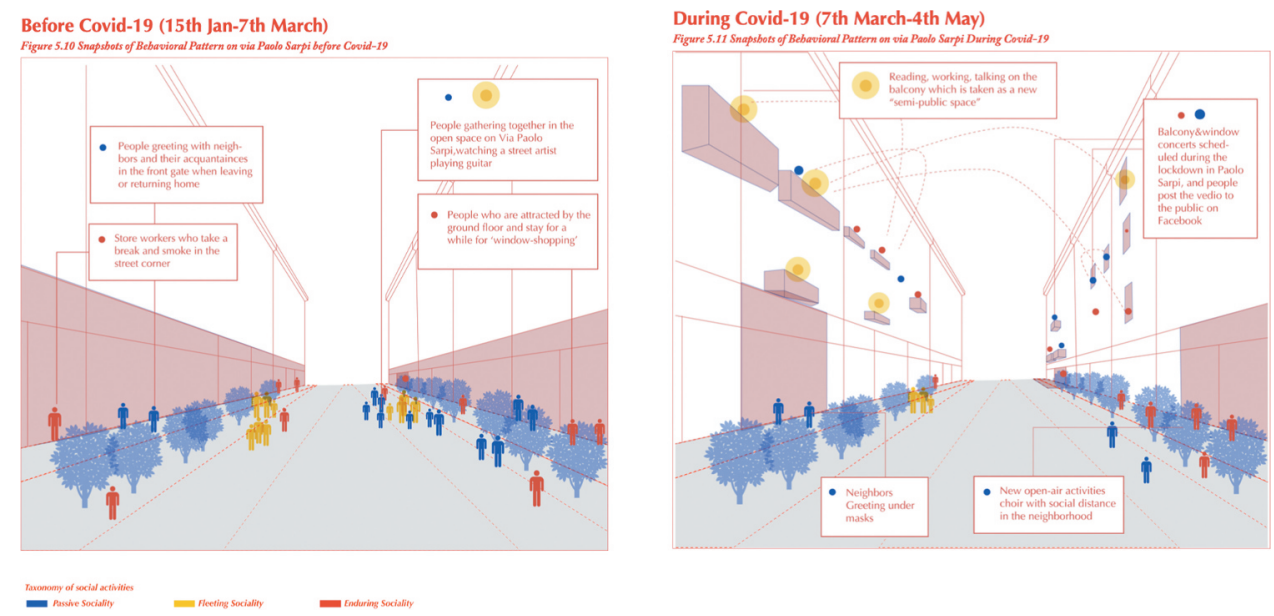

Figure 11. Snapshots of behavioral mapping on via Paolo Sarpi before and during COVID-19.
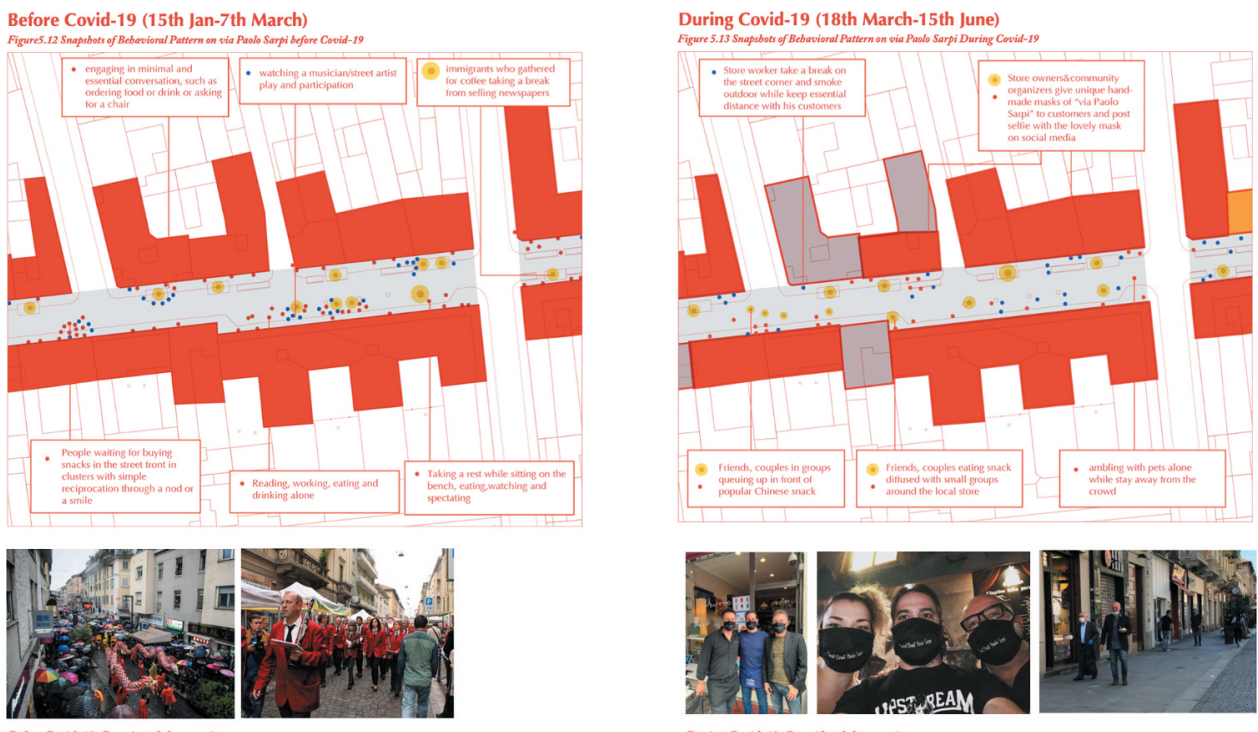

Figure 12. Snapshots of behavioral mapping on via Paolo Sarpi before and during COVID-19.

a single pattern of use to multiple ways of occupation. The crisis invoked new potentialities for people to reuse the environment that they took for granted. During the second phase of observation (from March 3rd to May 4th), for instance, the dining booths show more than three new patterns of occupation: Chinese community organization used it as s temporary station for distributing free masks to the passengers. Residents in Paolo Sarpi-no matters from wich cultural background-used them as a 'donation room' for collecting clothes and food; The homeless used it as a temporary shelter to take a rest, etc. Multi-level utilization results from the recession of the ground-floor business. The bottom-up management of commercial activities and street events leads to a personalization of spatial occupation in separate ways for dealing with street furniture, artifacts, beloved, and frequented places. From the case of Paolo Sarpi, it's 

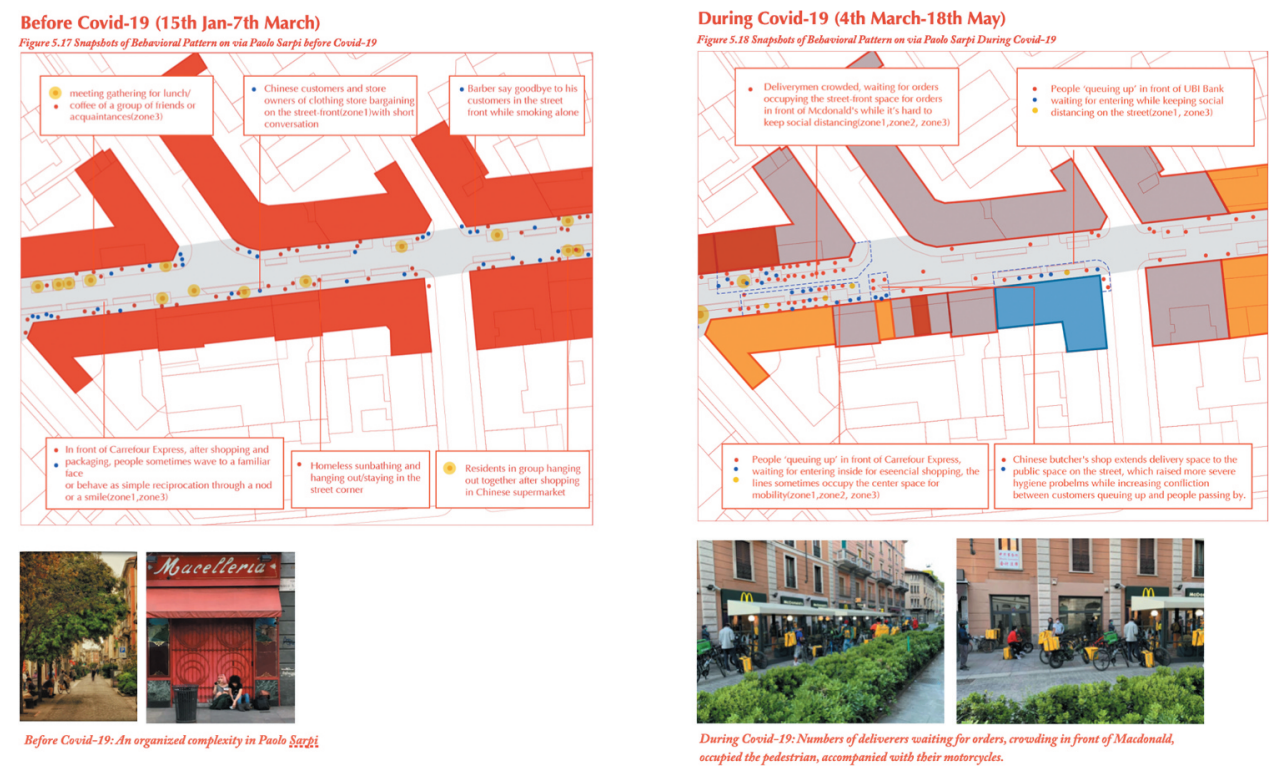

Figure 13. Snapshots of behavioral mapping on via Paolo Sarpi before and during COVID-19.

apparent that public space on the main street is stepping into the transition of individualized and introspective use. The use in the emergent moment varies from different users with respective aims: multiple behavioral demands such as helping others, survival, individual relaxation, looking for fares.

\section{Transition 2: Street ballet: From ground floor (2d) to multi-dimensions (3d)}

We used Jacob's idea of 'street ballet' to underline the role of the street as a stage for improvisations (Jacobs, 1961) and unexpected behaviors. Before COVID-19, the street ballet happens when people gathering, chatting, and playing on the ground floor. In the case of Paolo Sarpi, it's motivated by ground-floor businesses that used the articulated facade of the building to put out personalized signs and other artifacts, such as planters and flower boxes on the sidewalk, and change their window displays often to attract people (Laurence, 2006). While during COVID-19, this attraction doesn't vanish entirely but started switching from flat dimension on the ground floor to the whole level of dwelling buildings. One dweller said: "You could really feel a sense of wonder among those who were watching us from balconies". Another commented: "A lot of people thanked us for making them feel less lonely." In the last month, quarantined Italians have taken to their balconies to sing the national anthem in unison, launch fireworks, belt out opera, and applaud medical workers to boost the country's collective morale. Many of these public pandemic practices have quickly spread around the world. Therefore, the sudden shutdown of the ground floor interests completely changed the pattern of use from $2 \mathrm{D}$ level-oriented (use the ground space) to 3D (use all the space between buildings, from the ground to the air).

\section{Transition 3: Interactive aggregation-from centripetal power-driven to centrifugal power-driven}

Pleasure, joy, street festivals, and other occasional events that happened on the main street used to aggregate people together (Gehl \& Matan, 2009). Before COVID-19, the interactive 
aggregation in Paolo Sarpi was centripetal power-driven since people used public space to gather and stay close with each other, especially when there's a big festival on the street. Thanks to the pedestrian-oriented feature, via Paolo Sarpi can embrace a diversity of social celebrations with an inclusive culture. 'Street Festival' has been a great attraction to social behaviors: Open market on weekends, carnival parade with the orchestra, the Dragon Dance and Lion Dance organized by Chinese. On the contrary, during COVID-19, the interactive aggregation manifests as a centrifugal power-driven pattern: people tended to get social contact in small groups into the consideration of public health. With a revitalization of street life in the fourth phase (from May 18th), restaurant, cafe, clothing stores are allowed to reopen on the street, even though there are still many independent stores that stay closed. Due to hygiene and safety reasons, people preferred to remain in the street divided into small groups. Store owners and activists distributed hand-made masks with a local icon to customers, asking them to post a selfie with them on social media. Several couples come back to the street and engaged in eating food bought on local shops, but spreading on the sidewalk instead of gathering in front of the restaurant as usual. Neighbors shared their joy as small groups to the public on social media instead of attracting and inviting as more people as usual in the physical environment.

\section{Transition 4: From 'organized complexity' to 'erratic normality'}

In 1961, Jane Jacobs illustrated the problem of the city as "organized complexity," with the analogy of the life sciences (Jacobs, 1961). The inter-connected complexity also has driven the street as a place of territorialization, proximities, and overlaps. It became a social space where an elaborate act of dialogue, negotiation, and compromise among the occupants occur (Mehta, 2019a). However, during COVID-19, the spatial agreement of organized complexity transformed into unstable, erratic chaos due to unpredictable fluctuations in the pandemic era. To some degree, uncertainty is the new normal. Before COVID-19, the street life in Paolo Sarpi was presented as a paradigm of organized complexity, as Jane Jacobs illustrated, with multiple ethics and participants.

As one of the most attractive streets in Milan, people were waiting to buy snacks in the street front in clusters with simple reciprocation through a nod or a smile. Individuals eat, work, and drink alone in the local coffee shop. Some immigrants gathered for a drink, taking a break from selling newspapers, and tourists, and visitors from other regions watching a musician/street artist play, taking part in their performances. During COVID-19, with the collapsing and thriving of different industries, the previous spatial agreement has been broken through. Cities, according to P. Mehta and Dhindaw (2020), have come to a grinding halt for over a month now, and people continued to try to come to grips with the uncertainties. Studies like the one proposed in this paper should support an incremental knowledge about the social behaviors and their spatial patterns in times of new normality and help the public action in the definition of measures to support a safe, but vibrant and enjoyable urban life. Post-COVID-19 cities are testing ground, and only understanding what people do and how their living practices can adapt to new situations, planners, architects, and urban designers will produce a livable city of the future.

\section{Notes}

1. The research has been developed by Ying Fang in the context of her MS thesis in Politecnico di Milano, intitled "Managing Sociable Street in the New Normal" (A.Y. 2019/2020) and Mario Paris supported this study as supervisor. Tacking advantage of the produced materials, authors 
re-worked part of them, and the present paper is one of the first opportunity to disseminate part of the results. Although the authors cooperate in the writing of the paper, Mario Paris took main responsibility of the sections 1 and 2. Ying Fang of the section 3 and 4".

2. In Italy, the phenomenon of "social street", started in Bologna with the Facebook group "Residents in Via Fondazza-Bologna". It raised up to combat the general impoverishment of social relations in this consolidated urban area. Later on, online "social streets" were born to materialize offline encounters by contact online.

\section{ORCID}

Mario Paris (D) http://orcid.org/0000-0002-1129-3609

\section{References}

Acuto, M. (2020). Covid-19: Lessons for an Urban(izing) World. One Earth, 2(4), 317-319. https:// doi.org/10.1016/j.oneear.2020.04.004

Batty, M. (2020). The Coronavirus crisis: What will the post-pandemic city look like? EPB: Urban Analytics and City Science, 47(4), 547-552. https://doi.org/10.1177/2399808320926912

Bechtel, R. B., Marans, R. W., \& Michelson, W. (1987). Observation: The world under a glass. In R. B. Marans \& W. Michelson (Eds.), Methods in environmental and behavioral research (pp. 11-40). Van Nostrand.

Chretien, J. P., George, D., Shaman, J., Chitale, R. A., \& McKenzie, F. E. (2014). Influenza forecasting in human populations: A scoping review. PLoS One, 9(4), 4. https://doi.org/10.1371/journal.pone.0094130

Connolly, C., Ali, S. H., \& Keil, R. (2020). On the relationships between Covid-19 and extended urbanization. Dialogues in Human Geography, 10(2), 213-216. https://doi.org/10.1177/ 2043820620934209

Francis, M. (1984). Mapping downtown activity. Journal of Architecture and Planning Research, 1(1), 21-35.

Fuchs, C. (2020). "Everyday life and everyday communication in Coronavirus capitalism" communication, capitalism \& critique. Journal for a Global Sustainable Information Society, 18(1), 375-399. https://doi.org/10.31269/triplec.v18i1.1167

Gehl, J., \& Matan, A. (2009). Two perspectives on public spaces. Building Research and Information, 37(1), 106-109. https://doi.org/10.1080/09613210802519293

Ghel, J. (1987/2011). Life between buildings. Using public spaces. Island Press.

Goličnik, B., \& Thompson, W. C. (2010). Emerging relationships between design and use of urban park spaces. Landscape and Urban Planning, 94(1), 38-53. https://doi.org/10.1016/j.landurbplan. 2009.07.016

Hillier, B. (2012). The city as a socio-technical system: A spatial reformulation in the light of the levels problem and the parallel problem. In S. M. Arisona, et al. (Ed.), Digital urban modeling and simulation. Communications in computer and information science. (pp. 24-48). Springer:. https:// doi.org/10.1007/978-3-642-29758-8_3.

Ittelson, W. H. (1970). The use of behavioral maps in environmental psychology. In H. M. Prohansky, W. H. Ittelson, \& L. G. Rivlin (Eds.), Environmental psychology: Man and his physical setting (pp. 658-668). Rinehart \& Winston.

Jacobs, J. (1961). The death and life of great American cities. Random House.

Kucharski, A. J., Kwok, K. O., Wei, V. W. I., Cowling, B. J., Read, J. M., Lessler, J., Cummings, D. A., \& Riley, S. (2014). The contribution of social behavior to the transmission of influenza A in a human population. PLoS Pathogens, 10(6), e1004206. https://doi.org/10.1371/journal.ppat.1004206

Lai, Y., Yeung, W., \& Celi, L. A. (2020). Urban Intelligence for Pandemic Response: Viewpoint. JMIR Public Health and Surveillance, 6(2), 2. https://doi.org/10.2196/18873 
Lak, A., Shakouri, A., \& Maher, A. (2020, June 30). Resilient urban form to pandemics: Lessons from Covid-19. Medical Jurnal of the Islamic Republic of Iran 34(1), 34-71. https://doi.org/10.34171/ mjiri.34.68

Laurence, P. L. (2006). The death and life of urban design: Jane Jacobs, The Rockefeller Foundation and the new research in urbanism, 1955-1965. Journal of Urban Design, 11(2), 145-172. https:// doi.org/10.1080/13574800600644001

Lofland, L. H. (1998). The public realm: Exploring the city's quintessential social territory. Routledge.

Marcus, C. C., \& Francis, C. (Eds.). (1997). People places: Design guidelines for urban open space. John Wiley \& Sons.

Masten, A. S., \& Motti-Stefanidi, F. (2020). Multisystem Resilience for Children and Youth in Disaster: Reflections in the Context of Covid-19. Adversity and Resilience Science, 1(2), 95-106. https://doi.org/10.1007/s42844-020-00010-w

Mehta, P., \& Dhindaw, J. (2020) "Reconfiguring public spaces within the new normal" The Times of India, May, 11.

Mehta, V. (2007). Lively streets: Determining environmental characteristics to support social behavior. Journal of Planning Education and Research, 27(2), 165-187. https://doi.org/10.1177/ 0739456X07307947

Mehta, V. (2013). The Street. A Quintessential Social Public Space. Routledge.

Mehta, V. (2014). Evaluating public space. Journal of Urban Design, 19(1), 53-88. https://doi.org/10. 1080/13574809.2013.854698

Mehta, V. (2019). Space, Time, and Agency on the Indian Street. In M. Arefi, C. Kickert (Eds.), The Palgrave Handbook of Bottom-Up Urbanism (pp. 239-253). Palgrave Macmillan.

Mehta, V. (2019). Streets and social life in cities: A taxonomy of sociability. Urban Design International, 24(1), 16-37. https://doi.org/10.1057/s41289-018-0069-9

Mehta, V., \& Bosson, J. K. (2010). Third places and the social life of streets. Environment and Behavior, 42(6), 779-805. https://doi.org/10.1177/0013916509344677

Nitschke, J. P., Forbes, P., Ali, N., Cutler, J., Apps, M. A., Lockwood, P., \& Lamm, C. (2020). Resilience During Uncertainty. Greater Social Connectedness During Covid-19 Lockdown is Associated with Reduced Distress and Fatigue. PsyArXiv Preprints. https://doi.org/10.31234/osf. io/9ehm7

Peters, M. A. (2020). The plague: Human resilience and the collective response to catastrophe. Educational Philosophy and Theory, 1, I-IV. https://doi.org/10.1080/00131857.2020.1745921

Whyte, W. (1980). The social life of small urban spaces. Project for Public Spaces.

Wolf, M. (2016). Rethinking urban epidemiology: Natures, networks and materialities. International Journal of Urban and Regional Research, 40(5), 958-982. https://doi.org/10.1111/1468-2427.12381 